\title{
Coach's Expressed Positive Supportive Behaviour Linked to Client's Interest to Change: An Analysis of Distinct Coaching Phases
}

\author{
Theresa Will ${ }^{1}$ - Eva-Maria Schulte ${ }^{1} \cdot$ Simone Kauffeld $^{1}$
}

Published online: 8 March 2019

(c) The Author(s) 2019

\begin{abstract}
As coaching research has demonstrated, coach behaviour could influence the client. Hence, knowledge about 'how' a coach can influence the client during a coaching session, and more specifically, during distinct phases of coaching, is lacking. We attempt to fill this research gap (1) by considering active coach ingredients: coaches' expressed empathy and appreciative behaviour summarized as positive supportive behaviour, and (2) by taking single coaching phases (contact, exploration, operationalisation, conclusion phase) into account. Therefore, we analysed 52 videotaped coaching sessions by using the interactional tool act4consulting. First, to examine if a coach behaves differently in each phase, we analysed expressed positive supportive coach behaviour. Second, we analysed if the coach behaviour was significantly linked to client's interest to change. Third, we assumed that coach's expressed positive supportive behaviour is more positively linked to the client's interest to change in the exploration and in the operationalisation phase. Results yielded that coach behaviour differs significantly across all phases, and that expressed positive supportive coach behaviour in the contact, operationalisation, and conclusion phases was linked to the client's interest in change. A variance in the coach's behaviour on client's interest to change in the single phases could not be found.
\end{abstract}

Keywords Coaching phases $\cdot$ Supportive coach behaviour $\cdot$ Expressed empathy $\cdot$ Expressed appreciation $\cdot$ Interest to change

Theresa Will

theresa.will@de.ey.com

Eva-Maria Schulte

e.schulte@tu-bs.de
Simone Kauffeld

s.kauffeld@tu-bs.de

Department of Industrial/Organisational and Social Psychology, Technische Universität Braunschweig, Spielmannstr 19, 38106 Braunschweig, Germany 


\section{Positiv gezeigtes Unterstützungsverhalten durch den Coach ist verbunden mit dem Interesse an Veränderung des Klienten: Eine Analyse verschiedener Coaching Phasen}

\section{Zusammenfassung}

Wie die Coaching-Forschung gezeigt hat, kann das Verhalten des Coaches den Klienten beeinflussen. Dennoch fehlt aktuell das Wissen darüber, wie ein Coach den Klienten während einer Coaching-Sitzung und insbesondere in verschiedenen Phasen des Coachings beeinflussen kann. Wir versuchen, diese Forschungslücke zu schließen, indem wir (1) aktive Einflussvariablen des Coaches berücksichtigen: das ausgeprägte Empathievermögen und wertschätzende Verhalten des Coaches, das als positives Unterstützungsverhalten zusammengefasst wird, und (2) indem wir einzelne Coachingphasen (Kontakt-, Explorations-, Operationalisierungs-, Abschlussphase) berücksichtigen. Dazu haben wir 52 auf Video aufgezeichnete Coaching-Sitzungen mit dem Interaktionsinstrument act4consulting analysiert. Um zuerst untersuchen zu können, ob sich ein Coach in jeder Phase anders verhält, haben wir gezeigtes positives unterstützendes Coach-Verhalten analysiert. Zweitens analysierten wir, ob das Verhalten des Coaches signifikant mit dem Interesse des Klienten an Veränderungen geknüpft ist. Drittens gingen wir davon aus, dass das positive Unterstützungsverhalten des Coaches positiver mit dem Interesse des Klienten an Veränderungen in der Explorations- und in der Operationalisierungsphase verbunden ist. Die Ergebnisse zeigten, dass sich das Coach-Verhalten in allen Phasen deutlich unterscheidet und dass ein positives unterstuitzendes Coach-Verhalten in der Kontakt-, Operationalisierungs- und Abschlussphase mit dem Interesse des Klienten an Veränderungen verbunden war. Eine Abweichung im Verhalten des Coaches bezogen auf die Klienten Äußerungen zu Interesse an Veränderungen in den einzelnen Phasen konnte nicht festgestellt werden.

Schlüsselwörter Coaching Phasen · Unterstützendes Coach Verhalten · Gezeigte Empathie · Gezeigte Wertschätzung · Interesse an Veränderung

\section{Introduction}

Coaching is not only popular, but also shows significant positive effects on several outcomes, such as performance, work attitudes, well-being, and goal-directed self-regulation (Theeboom et al. 2013). By trying to understand the positive influence of coaching in more detail, previous research found two essential coach behaviours which are often mentioned as being the special influencing factors for relationship building between coach and client: (1) coach's expressed empathy (e.g., Baron and Morin 2009: Santor 2003) and (2) coach's expressed appreciative behaviour (e.g., Bluckert 2005; positive regard: Eggers and Clark 2000; nonpossessive regard: Kilburg 1997). Empathic behaviour is defined as cognitive empathy, which is characterized as paraphrasing and addressing the client's feelings (Will et al. 2016). By using empathic behaviour, the coach expresses his/her understanding of the internal state of the client and tries to understand the client's mind (e.g., Smith 2006). By expressing appreciative behaviour, the coach values the client's statements and encourages him/her to achieve the coaching target (Bluckert 2005).

Although both of these expressed positive supportive coach behaviours are emphasised to be important behaviours a coach should show (Kilburg 1997; Peltier 2001), scholars often use questionnaires which ask a coach or client for their perception of these behaviours (e.g., Baron and Morin 2009). Only a small amount of coaching research has actually analysed the real interaction, and has focused on the coaching process (e.g., Gessnitzer and Kauffeld 2015; Greif 2010; Ianiro and Kauffeld 2014; Ianiro et al. 2014, 2013; Klonek et al. 2016), with only one study focussing on empathic behaviour (Will et al. 2016).

Hence, in this connection, the analytical focus mostly lies on the whole coaching process, consisting of several sessions or on single coaching sessions. Up to now, deeper insight into single phases of a coaching session have been sparse. Although coaching models, such as the GROW (Whitmore 1996), the ACHIEVE (Dembkowski and Eldridge 2003), or the PRACTICE (Palmer 2008) model, help to gain deeper insights into the structure of a coaching session and thus show that different phases in one coaching session can be found, observation data is still missing. However, by using observational analyses, the real behaviour between coach and client can be better analysed, than for example, by use of questionnaire data (c.f., Baumeister et al. 2007).

To sum up, we are aware of the importance of expressed empathy and appreciative behaviour, but actually we do not know when a coach should show more or less of these behaviour patterns in order to support the client's ability and desire to change his/her behaviour, and, thus, to support his/her goal achievement. For this reason, in the current article we pursue three aims: First, to the best of our knowledge, we are the first to focus on different phases of a coaching session. We want to focus on the first coaching session as an initial contact because a good connection to the client is essential and could help to develop a good 
relationship (De Haan 2008). Second, the article is a direct response to the call for more research on objective process-based data (Möller and Kotte 2012). Third, the article not only focuses on a coaching session and takes single phases into account, but it also considers the influence of the coach's expressed positive behaviour pattern on a client's outcome variable (i.e., client's interest in changing). In the following, (1) we analysed the expressed positive supportive coach behaviour (i.e., expressed empathic and appreciative behaviour) for each of four single phases of a first coaching session, and (2) we investigated (a) the influence of the coach's expressed positive supportive behaviour during each phase on the interest of the client to change (as it is one of the main objectives and success factors within coaching) and (b) if there will be differences in the coach's influence on the client behaviour per phase.

\section{Theoretical Background}

\subsection{Zooming into the Process-Different Phases in Coaching}

Even though coaching definitions vary, most of them share the point of view that coaching is seen as a "collaborative relationship formed between coach and coachee for the purpose of attaining professional or personal developmental outcomes which are valued by the coachee' (Grant et al. 2010, p. 129). Despite a growing interest in coaching research in the last several years, and meta-analytic results supporting the positive influence of coaching (Grant et al. 2010; Jones et al. 2016; Theeboom et al. 2013), we still know little about the coaching ingredients and the influence of the coach's behaviour on the coachee (e.g., Bluckert 2005; De Haan et al. 2013; Will et al. 2016). In other words, we know that coaching works, but not how it works (e.g., Linley 2006).

In fact, the existing coaching studies often highlight the special role of the relationship as being one of the most crucial ingredients of coaching outcomes (Bluckert 2005). In order to answer the question of which ingredients might influence the relationship, some studies have examined critical moments in coaching (e.g., De Haan 2008; Day et al. 2008; De Haan et al. 2010). But even if these results offer valuable insights, such as that misunderstanding and anger affect the relationship between coach and client negatively (De Haan et al. 2010), most of these studies made use of questionnaires to answer the research questions. In line with other authors (Möller and Kotte 2012), we support the idea that in order to answer the question of how coaching works, we need to focus more on the process of a coaching session and need to analyse single phases, or even single fragments of an interaction in a coaching session. In line with this idea, some existing coaching models differentiate between single phases of a coaching session (Dembkoswaki and Eldridge 2003; Jackson and McKergow 2007; Palmer 2002, 2007; Whitmore 2004).

The GROW model, based on Whitmore (1996), is not only the most used and best known coaching model (Dembrowski and Eldridge 2003), but also is often the basis for further models, such as the ACHIEVE (Dembrowski and Eldridge 2003) or the PRACTICE model (Palmer 2007). The GROW model consists of the following four phases (Whitmore 2010): First, goal setting for the session for short (for the coaching session and days directly after coaching: e.g., what would the client get out of the session), and long-term planning (after finishing the coaching process: e.g., what are the next three action steps). The second phase focuses on reality checking to explore the actual situation, and letting the client describe the current status quo, which, for example, means naming the factors that determined the client's decision. Third, options and strategies for further progression and courses of action will be named. Finally, the focus lies on what, when, and by whom, so that a summary is created, action planning is named, and possible steps are outlined (for more information of the single phases, please see Whitmore 2010).

The GROW model, on the one hand, builds a model framework for a whole coaching process based on several coaching sessions, but, on the other hand, can also be transferred to one single coaching session (e.g., Whitmore 2010). Nevertheless, we believe that especially for the first session, which often builds the basis for the interaction between coach and client (Peltier 2001), the GROW model should be adapted because the phase in which coach and client get in touch with each other for the first time is not explicitly included in the GROW model. This means that it cannot be explicitly transferred to a first coaching session. That is why we combined the most striking factors of the existing GROW model and assimilated the model, especially the contact and the exploration phases, to a first coaching session:

1. Contact phase (adaptation: first contact, meaning that client and coach need to get to know each other; the relationship quality between coach and client develops for the first time; the goal of the first session will be presented; This phase is comparable to the first step, the ' $G$ ' of the GROW model).

2. Exploration phase (the coach tries to find out the reason why the client wants to make use of a coaching, goals should be expressed by using the SMART rule. Since 'the most important criterion for examining reality is objectivity' (Withmore 2010, p. 67). In this phase, the goals for the whole coaching process will be fixed. This phase is comparable to the second part 
of the $\mathrm{G}$, where long-term planning is discussed, and to the ' $\mathrm{R}$ ' of the GROW model.)

3. Operationalisation phase (The coach helps the client to locate where the client sees him/herself and determines possible goals; the coach uses a scale ranking from 0 to 10 for clarifying the current client's point of view and for defining coaching targets (based on Lancer et al. 2016). Additionally, sub-steps will be operationalised and steps for further progression and courses of action will be discussed, which is comparable to the ' $\mathrm{O}$ ' of the GROW model).

4. Conclusion phase (a summary of the session is made, to do's are discussed, and homework/action planning will be given. This step is comparable to the ' $\mathrm{W}$ ' step of the GROW model).

\subsection{Why Positive Expressed Supportive Coach Behaviour is the Key to Success}

Rogers (1951) pointed out that a therapist has to express unconditional regard (which is used in the same way as is appreciation) and accurate empathy toward the client to be effective. Both the clinical setting and the coaching context highlights these two behaviour pattern for successful coaching outcomes.

\subsubsection{Relevance of Expressed Empathy}

Although researchers have discussed a 2-factor structure of empathy consisting of emotional and/or cognitive empathy (e.g., Smith 2006), the special role of cognitive empathy for the coaching context has been especially emphasized (Lancer et al. 2016; Will et al. 2016). As cognitive empathy refers to understanding the mental state of a counterpart, it helps to form the relationship quality (BarrettLennard 1997). The important role of cognitive empathy is well established in therapy research: therapist's empathy is seen as a key change process variable (Bohart and Greenberg 1997). More precisely, empathy accounts for $9 \%$ of the variance in clinical therapy outcomes, which is much more than the effects of any other treatment intervention (Elliott et al. 2011).

Coaching research often highlights the special role of empathy, for example, as being a relevant coach behaviour that clients found helpful (Hall et al. 1999), or for effective coaching (Bluckert 2005; Lancer et al. 2016; Peltier 2001). However, up to now, little coaching research has examined the construct in detail. Referring to Will et al. (2016), it is not only important that a coach is empathic, but also that empathy needs to be expressed to the client. Initial results have supported the positive influence of expressed empathy on the coaching process as well as on the perceived empathy reported by the client.

\subsubsection{Relevance of Appreciative Coach Behaviour}

Beside the important role of expressed empathy, the coach's expressed appreciative behaviour is stated as being very fundamental for the interaction between coach and client (e.g., Bluckert 2005; Lancer et al. 2016). A coach has to understand what the client wants and has to assist him individually. Coach's expressed appreciation could help to support the client to achieve coaching goals (Bluckert 2005). Even though most of the current research findings dealing with positive regard are based on Rogers, overlapping terms such as 'affirmation, acceptance, warmth, support' (Farber and Lane 2001, p. 391) can be found. Because these words are all used in a similar way, in the following, we make use of the word expressed 'appreciation' which is mostly used within the coaching context.

Studies from a clinical context often underline the important role of appreciation as this seems to be one main characteristic a therapist should have (Rogers 1951). A psychotherapist's ability to provide appreciation is associated with therapeutic success (c.f., Farber and Doolin 2011). Moreover, appreciation not only builds the basis for other interventions and may be important by itself to effect positive client's change, but also helps a client to be felt understood by the therapist because, to clients, it is important to have the feeling of being appreciated by their therapist (Farber and Doolin 2011). Similar to the therapeutic context, also in the coaching context, the coach has to express his/her appreciation to the client. In order to show this behaviour pattern to a client, in line with other authors (Farber and Doolin 2011), we believe that therapists/coaches have to communicate these positive statements to the client to ensure that the client could perceive this appreciation. Under consideration of previous research, we define the word expressed appreciation for the coaching context as supporting the client's positive statements as well as expressing understanding.

As coach's expressed empathy and appreciative behaviour often have been mentioned to be important constructs that are linked to the relationship and to the client's outcome positively, in the following, we combine both constructs because, in research, both are often named in the same context (e.g., Bluckert 2005). Below, we talk about a positive behaviour pattern which a coach could use to support the client to achieve personal aims (Bluckert 2005) in a first coaching session. This study aims to examine the role of a coach's expressed empathy and appreciation within single phases of a first coaching session. 


\subsection{Coach's Expressed Positive Supportive Behaviour Pattern in Different Coaching Phases}

Previous research supports the influence of the coach's behaviour on the client (e.g., De Haan et al. 2010; Will et al. 2016). However, we do not know if the coach should adapt his/her supportive behaviour due to the phase of the coaching session. Examining executive coaching, Wasylyshyn (2003) found the ability to form a strong connection to the client as the top characteristic for effective coaches. To achieve this goal, it is important to construct a full picture of the client and to understand the client's actual situation (Lancer et al. 2016). Up to now, we do not know in which phase of a first coaching session it is especially important to be empathic or appreciative, and what factors contribute to goal achievement. The GROW model (Whitmore 2010) and our adaption to the first coaching session as introduced above, consists of several phases which differ in their characterisation. In the contact phase (i.e., first personal contact at the beginning of the first session), a coach needs to build a relationship basis between the client and him-/ herself. This might be easier when expressing positive supportive behaviour to the client in order to create a pleasant atmosphere (c.f. Rogers 1951). In order to be authentic, the coach's expressed positive supportive behaviour should not overwhelm the client. In the exploration and in the operationalisation phase, the coach has to express positive supportive behaviour because the coach has to encourage the client to explain the target in a detailed manner (Whitmore 2010) (exploration phase), but also has to motivate him/her to fix the target (in the operationalisation phase). The final conclusion phase of a coaching session focusses on a summary of the session and on pieces of homework, which will be given to the client by the coach. Therefore, the coach also has to support the client, but perhaps less because the client does not 'work' actively on a target, but 'only' receives to do's. Taken together, we expect coaches to show adaptive positive supportive behaviour in different coaching phases. Thus, we assume that:

Hypothesis 1 The coach's expressed positive supportive behaviour differs across the contact, the exploration, the operationalisation, and the conclusion phase.

\subsection{Positive Effects of the Coach's Positive Supportive Behaviour}

If we act on the assumption that coach behaviour differs within the single coaching phases, the question might arise: When is it important to show specific coach behaviour bearing client's coaching goal achievement in mind? Most of the existing coaching outcome studies have dealt with goal-specific related issues, such as increased self-awareness, self- acceptance, improved work-life balance, and well-being. Even though at first sight these outcome goals seem to not be similar, all of them share the element that the client often aims at changing his or her previous behaviour (Grant 2001; Griffiths 2005; Quick and Macik-Frey 2004). A first step for changing behaviour is the client's motivation or interest to change (Miller and Rose 2009), which is shown in the coaching session by expressing the volition of changing behaviour verbally (Hoppe 2013). From motivational interviewing research, we know that especially for therapy outcome, it seems very important that the client verbalises his or her motivation to change on his or her own without being pushed by a therapist (Miller and Rose 2009). Motivational interviewing research has shown that in a first step of changing a behaviour, a client first needs to have the motivation to do so (Miller and Rose 2009). Comparable to coaching, this might be statements that the client verbalises within the coaching session. This form of change talk could promote successful therapy (Miller and Rose 2009; Miller and Rollnick 2002). Similar to this understanding of motivational interviewing, Rogers also underlines the importance of a supportive atmosphere created by the therapist in which the client has the chance to express his or her own reason and his or her own opinion of changing behaviour (Rogers 1959). As the therapist's supportive behaviour could influence the client's behaviour and the client's motivation to change (Miller and Rollnick 2002; Moyers and Martin 2006), it might be important that the coach expresses positive supportive behaviour in the contact phase, where the goal of the first session is presented. So, the coach's expressed positive supportive behaviour could help the client to arouse interest to change. In the exploration phase, the coach's positive supportive behaviour seems to be important for arousing a client's interest to change because goals will be defined in this phase, which is a first step in the direction of a client's behaviour change. In the operationalisation phase in which the client identifies his targets, a coach's positive supportive behaviour can also help the client to recognise interest to change because in this phase, sub steps for further progression will be argued. For example, a client sees himself actually on a 5 (of 10) but wants to achieve an 8 within the coaching process. In the conclusion phase, the coach's expressed positive supportive behaviour might be linked to client's interest to change because here, a summary of the first coaching session and homework will be given. This might also stimulate the client to communicate interest to change.

All in all, we expect positive effects of coach's positive supportive behaviour to be linked to the client's interest to change per single phase. Therefore, for hypothesis 2 , we assume: 
Hypothesis 2 Demonstrated positive supportive coach behaviour is significantly positively linked to the spoken client's interest to change in the contact, the exploration, the operationalisation, and the conclusion phases.

Based on the assumption that coach's expressed positive supportive coach behaviour is positively linked to client's interest to change per phase, we further focus on potential differences within these correlations. In the contact phase a high positive supportive level of expressed coach behaviour might not be natural to the client, because it is the first contact between client and coach, which means that it is first important to get to know each other and to build initial trust. In contrast, in the two following phases it is especially important for the coach to express his/her supportive behaviour to facilitate client's explanation of his or her goals (exploration phase) as well as client's commitment to these goals and steps to reach these goals (operationalisation phase). So we expect higher correlations in these two phases than in the contact phase. Finally, in the conclusion phase coach's positive supportive is important to underline client's positive learnings of the actual session (summary). However, this phase also focuses on client's homework, which means that the coach has-compared to the two previous phases-more an explanatory role. We therefore expect that the expressed positive supportive coach behaviour is most important in the exploration and the operationalisation phases and thus assume:

Hypothesis 2a Demonstrated positive supportive coach behaviour is more strongly positively linked to the spoken client's interest to change in the exploration and in the operationalisation phase than in the contact and conclusion phase.

\section{Method}

\subsection{Design and Procedure}

Data was collected in the context of a coaching education training, which took place at two universities in Northern and Southern Germany. Clients were recruited via oral promotion, fliers at the universities' campus, or via advertisement on the universities' websites. After clients were informed, they could participate in the coaching voluntary. All coaches were psychologists with a Bachelor degree and completed a training of about $200 \mathrm{~h}$ before they were allowed to coach an unknown client. The coaching training lasted two semesters and consisted of (1) theoretical basic coaching knowledge, such coaching concepts or coaching techniques, (2) practical training with a peer via, for example, roleplay, (3) practical training and self-awareness as a client, (4) practical training as a coach, and (5) supervision with experienced coaches who were available all the time and accompanied the whole training process. After having finished their coaching training, all coaches completed a coaching process with a randomly assigned client. The coaching addressed career-related issues and lasted for five sessions. For the present study, we videotaped the first session because this session is very special for the ongoing process. The guidelines for the first session recommended establishing a good relationship to the client and clarifying the client's request, including goal exploration, operationalisation, and conclusion, by summarizing and giving homework to the client.

\subsection{Participants}

We analysed 52 coaching dyads. Participation was certified after the process and part of the coaches' curriculum. An average session lasted $83.15 \mathrm{~min}(S D=26.74$, $\operatorname{Min}=39$, Max =130). The age of the coaches ranged from 21-42 years $(M=24.69, S D=3.67)$. In all, $94.2 \%$ were female $(n=49)$ and $5.8 \%$ were male $(n=3)$. The clients who had applied for a career-coaching process were young professionals or students before finishing their Bachelor or Master degree. The clients' average age was 25.23 years, which ranged from 21-39 years. Here, $55.8 \%$ were female $(n=29)$ and $44.2 \%$ were male $(n=23)$. All participants gave their written consent for being videotaped and for scientific analyses.

\subsection{Measures}

Interactional Analyses By using the coding scheme Advanced Interaction Analysis for Consulting (act4consulting; e.g., Gessnitzer and Kauffeld 2015; Will et al. 2016; based on act4teams, Kauffeld and Lehmann-Willenbrock 2012) and the software INTERACT (Mangold 2010), trained coders cut and coded the 52 coaching sessions into smallest units (max. 20s per statement; a 1-hour coaching consists of about 800 units on average). Such a unit is defined as the smallest meaningful statement that can be understood by the counterpart of the interaction (Bales 1950). After the coders cut the units, each unit was assigned to either coach or client and received a behavioural code based on act4consulting. In this paper, we focused on the following codes: paraphrasing, addressing the client's feelings and appreciation as well as client's interest to change. All coders received a 50-hour training from an experienced coder before they started to code on their own. Furthermore, coders had regularly supervised meetings to address questions. Inter-rater reliability was good and at $k=0.70$ (Landis and Koch 1977). We standardised all code 
Table 1 Correlation analyses per single coaching phase and Steiger's z-values

\begin{tabular}{lllll}
\hline & $\mathrm{r}$ & \multicolumn{2}{l}{ Steiger's z values compared to correlation in the phase } \\
& & Exploration & Operationalization & Conclusion \\
\hline Contact phase & $0.36^{* *}$ & 1.135 & -0.017 & 0.044 \\
Exploration phase & 0.15 & - & -1.123 & -1.042 \\
Operationalization phase & $0.36^{* *}$ & - & - & 0.061 \\
Conclusion phase & $0.35^{*}$ & - & - & - \\
\hline
\end{tabular}

$N=52$

$r$ correlation between positive supportive coach behavior and client's interest to change in the different phases

$* p<0.05 ; * * p<0.01$; two-tailed for correlations and one-tailed for $\mathrm{z}$ values

frequencies to compare the amount of coach's and client's behaviour on the length of the coaching session.

\subsection{Coaching Phases}

All coaching phases where separated by making use of our theoretically based definitions per phase. More detailed information is given above in this article. By means of these definitions, we qualitatively cut the coaching session into four parts (contact, exploration, operationalisation, and conclusion phase).

\subsection{Expressed Positive Supportive Coach Behaviour}

Following Will et al. (2016) we built the cumulative value between the codes paraphrasing which means repetition of aforesaid into the coach's own words and prophase client's formulations/statements (e.g., 'Let me paraphrase your last statements. You said that ...') and addressing the client's feeling which means that the coach addresses or asks for the client's feelings (e.g., 'How are you today?'), which are representative for expressed empathy and due to the code appreciation which stands for that the coach shows thanks and respect and addresses understanding for the client (e.g., 'This was pretty good.') (e.g. Bluckert 2005) because these behaviour patterns are often named in the same context as being special influence variables for coaching interaction. To account for differences, we standardised the statements per phases to a 15-minute period.

\subsection{Interest to Change}

The code interest to change was used to analyse the verbal statements of the client in order to capture his motivation to change the actual behaviour. More specifically, this means that the client is addresses positive statements regarding changing behaviour or that the client shows self-engagement or that the client expresses openness for change (e. g., 'I will try this.'). We standardised the statements per phases to a 15-minute period.

\section{Results}

In order to test the first hypothesis where we wanted to examine whether the expressed positive supportive behaviour of the coach differed among the phases, we used a repeated measures ANOVA with a Greenhouse-Geisser correction, which determined that the coaching phases (positive supportive behaviour per phase as the withinsubjects) yielded a statistically significant variation between the phases $(F(1.97,100.68)=49.33, p<0.001)$. Posthoc Bonferroni-adjusted analysis also showed a significant difference (at $p<0.005$ ) between all coaching phases. By analysing the descriptive statistics, positive supportive coach behaviour in the exploration phase showed the highest mean value $(M=4.03, S D=2.57)$. The second highest mean value can be seen in the operationalisation phase $(M=2.62, S D=2.37)$, whereas in the conclusion $(M=0.84$, $S D=0.84)$ and in the contact phase, the means values were lower $(M=0.17, S D=0.19)$. The positive supportive coach behaviour is standardized to $15 \mathrm{~min}$. Regarding Hypothesis 1, these results support our assumption that in all phases, the expressed positive supportive coach behaviour differed.

In order to test the second hypothesis, bivariat Pearson correlation analyses were conducted using the software SPSS (Version 23). We tested per phase in what way a client's interest to change was linked to the coach's expressed supportive behaviour. Results indicated that the coach's expressed positive supportive behaviour was positively significantly linked to the client's interest to change in the contact phase $(\mathrm{r}=0.36, p<0.01)$, in the operationalisation phase $(\mathrm{r}=0.36, p<0.01)$, and in the conclusion phase $(\mathrm{r}=0.35, p<0.01)$, except in the exploration phase (n. s.). For more information, please see Table 1 . As only three of four tested regressions were significant, we could only partly support Hypothesis 2.

\section{Discussion}

The present study has addressed current calls for more process-based analyses in coaching and has given an answer to the question of what really happens in a coaching session. 
Whereas the GROW model from Withmore (e.g. 2010) does not explicitly focus on a first session and so does not take the first contact of coach and client into account, we assimilated the model, specifically the first (contact) and the second (exploration) of the four phases (contact, exploration, operationalisation, and conclusion). The main objective of this study was to focus on and analyse not only different coaching phases, but more specifically, the expressed positive supportive coach behaviour and its influence on the coaching outcome, such as a client's interest to change. We concentrated on the expressed positive supportive coach behaviour because it is often named as being special for the interaction with the client, but up to now, this behaviour has not been objectively researched. Likewise, as we know from psychotherapeutic research, the client's interest to change is mainly the most important and successful outcome of a session. This is why, we analysed the influence of the expressed positive supportive coach behaviour on the client's interest to change in order to tie in the current small amount of process based research in coaching. Results have shown a significant difference between the expressed coach behaviour in the single phases. Findings have pointed out that a coach adapts his/her behaviour per phase. In accordance with existing coaching research (e.g., Kilburg 1997), our results support the idea that a coach has to behave individually to support his/her client best and to provide a supportive relationship (Kilburg 1997). Behavioural coding showed that the expressed positive supportive coach behaviour influences the client's interest to change in the contact, operationalisation, and conclusion phases. Motivational Interviewing literature also underlines the findings that a therapist/counsellor can influence the client's change talk (Miller and Rollnick 2002). As in every phase, the topics change-for example, in the contact phase where coach and client first meet vs. in the operationalisation phase where the client's goals are fixed-the coach's expressed positive supportive behaviour could help the client by stating interest to change the actual behaviour and the actual situation. The results have not underpinned that coach's behaviour is more strongly linked to the client's interest to change in the exploration and in the operationalisation phase than in the two other phases. These findings show that coaches always have to show this supportive behaviour and need not to differ in their expressed behavioural intensity.

\subsection{Theoretical and Practical Implications}

Our findings have several implications for coaching research and the coaching practice. The study offers various contributions about how to measure coaches expressed supportive behaviour and client's interest to change. By analysing the codes paraphrasing, addressing the client's feelings and appreciation as well as interest to change, the findings have shown in a very objective manner (videobased objective data analyses) how coach and client interact in a coaching session and how they behave directly. By using video-based data, we could shed light on an innovative method of analysing the behaviour of coach and client. Additionally, now we not only know if coach and client show these behaviour pattern, but more specifically, we know when a coach has to express positive supportive coach behaviour. This means that we could answer more the question of what really happens within an interaction between coach and client now. The observed behaviour here is based on unbiased analyses and is even more objective than any other perception-based method (c.f., Baumeister et al. 2007).

Additionally, the importance of zooming into single coaching phases has been demonstrated. As we have shown, the separation and differentiation into single phases is necessary as not only the content of the single phases differs, but also the coach has to react individually to the client for helping him/her assemble the interest to change. As a first coaching session often assumes a special role as the first contact between coach and client, and the pathway for further sessions is built here, the new adaption of the GROW model now represents a more specific phase of the model than in the original model. This could be an initial point for future studies, which would consider more detailed process-based data. The findings of this study not only shed light on the behaviour of coach and client, they also underpin the importance of the relationship quality and the influence of coach behaviour on outcome variables.

Beside the theoretical findings, the study also offers new practical insights. One of the common concerns which coaches with a new client share is the question of whether they are able to form a strong connection to their client or if there will be a client with whom a coach could not work with (Bluckert 2005). In order to foster self-assurance, the study's findings offer helpful advice. In concrete terms, a coach's expressed positive supportive behaviour pattern, such as paraphrasing, addressing the client's feelings, and appreciation, can quickly and easily be learned. That is why these findings should be integrated more explicitly into coaching trainings. In addition, experienced coaches could also benefit from the study's findings because even if they knew before about these positive supportive behaviour pattern, they now know when they should express supportive behaviour, and that expressing positive supportive behaviour in the exploration phase has no significant influence on the client's interest to change. For this reason, they should especially express these behaviour pattern in the contact, the operationalisation, and the conclusion phase in order to support their client by addressing interest to change. Additionally, they now know that the expressed 
positive supportive behaviour is not more strongly positively linked to the client's interest to change in special phases.

In order to refer to coaching quality assurance, the results of our study contribute to ensuring that specific coach behaviours lead to client changing behaviour. Under consideration of professional coaching skills, these behaviour patterns need to be kept in mind, and more specifically, need to be expressed to the client.

All in all, this study is a first attempt to look into single coaching phases under consideration of coach's expressed positive supportive behaviour, and its influence on the client's changing behaviour.

\subsection{Limitations and Future Research}

As it is in every empirical study, our study has some limitations. First, the sample consists of younger coaches who have not gained that experience comparable to coaches who work longer in this field. However, the coaches from our sample have participated in an extensive coaching training with about $200 \mathrm{~h}$. Even if the study's sample does not represent the large diversity of professionals working in the coaching context, the study's sample is representative of a rising number of psychologists working in the current coaching market with a university qualification in coaching psychology (Grant et al. 2010). Future research could benefit from our findings of the study, but could also make use of another sample to analyse whether there will be differences with, for example, a management coach, who has another background similar to the coaches in our sample.

Second, examining expressed positive supportive coach behaviour, we focused on one main important influence factor a coach could use to support the client and to achieve a positive outcome. Notwithstanding, further research is needed in this context of empathy and appreciation in coaching for having the opportunity to examine if there could be an interplay within these two variables. Additionally, even more detailed information could be gained by not only using video-based data analyses but also by combining video-based data with questionnaires for having even more insights.

Third, the study explicitly focuses on the first session, which is the basis for the interaction between coach and client. Hence, future research could benefit from findings based on other sessions as well. Even if the following sessions do not assume the same special role as does the first session, research should focus on other coaching sessions and their special phases, such as the last session, where coach and client finish the coaching process. By conducting this research, it is possible to not only examine a client's interest to change, but also the client's real changed behaviour within the coaching process. With these findings there is the opportunity to provide information about how much a coach should express positive supportive behaviour in the first session, and what influence this could have on the following sessions.

Despite these limitations, our study is the first attempt to look into the coaching process considering both coach's and the client's behaviour, not only per single session, but also more detailed per coaching phases. Although the findings are only an initial research step, we now know that coach's expressed positive behaviour differs within single phases, and that there is initial indication of positive influence from the coach's behaviour toward and for the client.

Open Access This article is distributed under the terms of the Creative Commons Attribution 4.0 International License (http:// creativecommons.org/licenses/by/4.0/), which permits unrestricted use, distribution, and reproduction in any medium, provided you give appropriate credit to the original author(s) and the source, provide a link to the Creative Commons license, and indicate if changes were made.

Publisher's Note Springer Nature remains neutral with regard to jurisdictional claims in published maps and institutional affiliations.

\section{References}

Bales, R.F. (1950). Interaction process analysis: A method for the study of small groups. Chicago: University of Chicago Press.

Baron, L., \& Morin, L. (2009). The coach-coachee relationship in executive coaching: A field study. Human Resource Development Quarterly, 20, 85-106. https://doi.org/10.1002/hrdq.20009.

Barrett-Lennard, G. T. (1997). The recovery of empathy-toward others and self. In A.C. Bohart \& L.S. Greenberg (Eds.), Empathy reconsidered: New directions in psychotherapy (pp. 103-121). Washington, DC: American Psychological Association.

Baumeister, R. F., Vohs, K. D., \& Funder, D. C. (2007). Psychology as the science of selfreports and finger movements: Whatever happened to actual behavior? Perspectives on Psychological Science, 2, 396-403. https://doi.org/10.1111/j.1745-6916.2007.00051.x.

Bluckert, P. (2005). Critical factors in executive coaching-the coaching relationship. Industrial and Commercial Training, 37, 336-340. https://doi.org/10.1108/00197850510626785.

Bohart, A.C., \& Greenberg, L.S. (1997). Empathy reconsidered: New directions in psychotherapy. Washington, DC: American Psychological Association. https://doi.org/10.1037/10226-000.

Day, A., De Haan, A., Sills, C., Bertie, C., \& Blass, E. (2008). Coaches' experience of critical moments in the coaching. International Coaching Psychology Review, 3(3), 207-218.

Dembkowski, S., \& Eldridge, F. (2003). Beyond GROW: A new coaching model. The International Journal of Mentoring and Coaching, 1(1), 4-8.

Eggers, J.H., \& Clark, D. (2000). Executive coaching that wins. Ivey Business Journal, 65(1), 66-70.

Elliott, R., Bohart, A. C., Watson, J. C., \& Greenberg, L. S. (2011). Empathy. In J. Norcross (Ed.), Psychotherapy relationships that work (2nd edn., pp. 132-152). New York: Oxford University Press.

Farber, B. A., \& Doolin, E. M. (2011). Positive regard and affirmation. Psychotherapy relationships that work, 2, 168-186. https://doi. org/10.1093/acprof:oso/9780199737208.003.0008.

Farber, B.A., \& Lane, J. S. (2001). Positive regard. Psychotherapy: Theory, Research, Practice, Training, 38(4), 390-395. https://doi. org/10.1037/0033-3204.38.4.390. 
Gessnitzer, S., \& Kauffeld, S. (2015). The working alliance in coaching: Why behavior is the key to success. Journal of Applied Behavioral Science, 51(2), 177-197. https://doi.org/10.1177/ 0021886315576407.

Grant, A.M. (2001). Towards a psychology of coaching. New South Wales: University of Sydney.

Grant, A. M., Passmore, J., Cavanagh, M. J., \& Parker, H. M. (2010). The state of play in coaching today: A comprehensive review of the field. International review of industrial and organizational psychology, 25(1), 125-167. https://doi.org/10.1002/ 9780470661628.ch4.

Greif, S. (2010). A new frontier of research and practice: Observation of coaching behaviour. Coaching Psychologist, 6(2), 21-29.

Griffiths, K. (2005). Personal coaching: A model for effective learning. Journal of Learning Design, 1(2), 55-65.

De Haan, E. (2008). "I doubt therefore I coach"-Critical moments in coaching practice. Consulting Psychology Journal: Practice and Research, 60(1), 91-105.

De Haan, E., Bertie, C., Day, A., \& Sills, C. (2010). Clients' critical moments of coaching: Toward a "client model" of executive coaching. Academy of Management Learning \& Education, 9(4), 607-621.

De Haan, E., Duckworth, A., Birch, D., \& Jones, C. (2013). Executive coaching outcome research: The contribution of common factors such as relationship, personality match, and self-efficacy. Consulting Psychology Journal, 65, 40-57. https://doi.org/10.1037/ a0031635.

Hall, D. T., Otazo, K. L., \& Hollenbeck, G.P. (1999). Behind closed doors: What really happens in executive coaching. Organizational Dynamics, 27, 39-53. https://doi.org/10.1016/S00902616(99)90020-7.

Hoppe, D. (2013). What happens in consulting? A microanalytical investigation of the interaction between consultant and client. Braunschweig: Technische Universitaet Braunschweig. Doctoral dissertation

Ianiro, P. M., \& Kauffeld, S. (2014). Take care what you bring with you: How coaches' mood and interpersonal behavior affect coaching success. Consulting Psychology Journal, 66, 231-257. https://doi. org/10.1037/cpb0000012.

Ianiro, P.M., Lehmann-Willenbrock, N., \& Kauffeld, S. (2014). Coaches and clients in action: A sequential analysis of interpersonal coach and client behavior. Journal of Business and Psychology, 30, 435-456. https://doi.org/10.1007/s10869-0149374-5.

Ianiro, P. M., Schermuly, C. C., \& Kauffeld, S. (2013). Why interpersonal dominance and affiliation matter: An interaction analysis of the coach-client relationship. Coaching: An International Journal of Theory Research and Practice, 6, 25-46. https://doi.org/10. 1080/17521882.2012.740489.

Jackson, P.Z., \& McKergow, M. (2007). The solutions focus: Making coaching \& change Simple (2nd edn.). London: Nicholas Brealey.

Jones, R. J., Woods, S. A., \& Guillaume, Y.R. (2016). The effectiveness of workplace coaching: A meta-analysis of learning and performance outcomes from coaching. Journal of Occupational and Organizational Psychology, 89(2), 249-277.

Kauffeld, S., \& Lehmann-Willenbrock, N. (2012). Meetings matter: Effects of team meetings on team and organizational success. Small Group Research, 43, 130-158. https://doi.org/10.1177/ 1046496411429599.

Kilburg, R. (1997). Coaching and executive character: Core problems and basic approaches. Consulting Psychology Journal: Practice and Research, 49, 281-299. https://doi.org/10.1037/1061-4087. 49.4.281.

Klonek, F. E., Wunderlich, E., Spurk, D., \& Kauffeld, S. (2016). Career counseling meets motivational interviewing: A sequential analysis of dynamic counselor-client interactions. Journal of Vocational Behavior, 94, 28-38.

Lancer, N., Clutterbuck, D., \& Megginson, D. (2016). Techniques for coaching and Mentoring. London: Routledge.
Landis, J.R., \& Koch, G.G. (1977). The measurement of observer agreement for categorical data. Biometrics, 33, 159-174. https:// doi.org/10.2307/2529310.

Linley, P. A. (2006). Coaching Research: Who? What? Where? When? Why? International Journal of Evidence Based Coaching and Mentoring, 4(2), 1-7.

Mangold International GmbH (2010). INTERACT quick start manual V2.4. www.mangold-international.com

Miller, W.R., \& Rollnick, S. (2002). Motivational interviewing: Preparing people for change (2nd edn.). New York: Guilford.

Miller, W.R., \& Rose, G. S. (2009). Toward a theory of motivational interviewing. American psychologist, 64(6), 527-537. https://doi. org/10.1037/a0016830.

Möller, H., \& Kotte, S. (2012). Die Zukunft der Coachingforschung. Organisationsberatung, Supervision, Coaching, 18(4), 445-456. https://doi.org/10.1007/s11613-011-0256-7.

Moyers, T. B., \& Martin, T. (2006). Therapist influence on client language during motivational interviewing sessions: Support for a potential causal mechanism. Journal of Substance Abuse Treatment, 30, 245-251.

Palmer, S. (2002). Cognitive and organisational models of stress that are suitable for use within workplace stress management/ prevention coaching, training and counselling settings. The Rational Emotive Behaviour Therapist, 10, 15-21.

Palmer, S. (2007). PRACTICE: A model suitable for coaching, counselling, psychotherapy and stress management. The Coaching Psychologist, 3, 71-77.

Palmer, S. (2008). The PRACTICE model of coaching: Towards a solution-focused approach. Coaching Psychology International, 1(1), 4-8.

Peltier, B. (2001). The Psychology of executive coaching: Theory and application. New York: Taylor \& Francis.

Quick, J., \& Macik-Frey, M. (2004). Behind the mask coaching through deep interpersonal communication. Consulting Psychology Journal: Practice and Research, 56(2), 67-74.

Rogers, C. R. (1951). Client-centered therapy. Boston: Houghton-Mifflin.

Rogers, C. R. (1959). A theory of therapy, personality and interpersonal relationships as developed in the client centered framework. In S. Koch (Ed.), Psychology: A study of a science: Formulations of the person and the social context 3rd edn. New York: McGraw-Hill.

Santor, D. A. (2003). Review of Emotion-focused therapy: Coaching clients to work through their feelings. Canadian Psychology, 44(1), 76-77. https://doi.org/10.1037/h0088062.

Smith, A. (2006). Cognitive empathy and emotional empathy in human behavior and evolution. The Psychological Record, 56, 3-21.

Theeboom, T., Beersma, B., \& van Vianen, A.E.M. (2013). Does coaching work? A metaanalysis on the effects of coaching on individual level outcomes in an organizational context. Journal of Positive Psychology, 9, 1-18. https://doi.org/10.1080/17439760. 2013.837499.

Wasylyshyn, K.M. (2003). Executive coaching: An outcome study. Consulting Psychology Journal: Practice and Research, 55, 94-106. https://doi.org/10.1037/1061-4087.55.2.94.

Whitmore, J. (1996). Coaching for performance (2nd edn.). London: Nicholas Brealey Publishing.

Whitmore, J. (2004). Coaching for performance: GROWing people, performance and purpose (3rd edn.). London: Nicholas Brealey Publishing.

Whitmore, J. (2010). Coaching for performance: Growing human potential and purpose: The principles and practice of coaching and leadership. London: Nicholas Brealey Publishing.

Will, T., Gessnitzer, S., \& Kauffeld, S. (2016). You think you are an empathic coach? Maybe you should think again. The difference between perceptions of empathy vs. empathic behaviour after a person-centered coaching training. Coaching: An International Journal of Theory, Research and Practice, 9(1), 53-68. https:// doi.org/10.1080/17521882.2016.1143023. 